\title{
Spontaneous electrical activity of guinea-pig sinoatrial cells under modulation of two different pacemaker mechanisms
}

\author{
Francesca Cacciani, Massimiliano Zaniboni \\ Department of Biosciences, University of Parma, Italy
}

\begin{abstract}
The main cellular determinants of cardiac automaticity are the hyperpolarization-activated cationic current $\mathrm{I}_{\mathrm{f}}$, and the electrogenic $\mathrm{Na}^{+} / \mathrm{Ca}^{2+}$ exchanger which generates an inward current after each action potential (AP). Our goal was to evaluate their relative role in pacemaking, by means of application of Ivabradine (IVA) (specific $\mathrm{I}_{\mathrm{f}}$ blocker) and Ryanodine (RYA) (known to abolish calcium transient) on enzimatically isolated guinea-pig pacemaker cells. Spontaneous APs were recorded in patch-clamp whole cell configuration at $36^{\circ} \mathrm{C}$ from 7 cells perfused with the following sequence of solutions: physiological normal tyrode (NT), IVA $3 \mu \mathrm{M}$, NT and RYA $3 \mu \mathrm{M}$. Cycle length (CL, ms) and diastolic depolarization rate (DDR, V/s) were also calculated. Both blockers displayed similar effects, increasing CL (by 27 and $30 \%$, respectively), and decreasing DDR (by 34 and $42 \%$ ) with respect to NT exposure. These results suggest that both mechanisms are involved into pacemaking mechanism at a similar degree.
\end{abstract}

\section{Introduction}

Cardiac rhythm is established by spontaneous electrical activity of pacemaker cells, located in the sinoatrial (SA) node. The origin of this automaticity has long been investigated, and more recently a so called double clock theory has been proposed. According to this theory, spontaneous beat is caused by two main mechanisms: ${ }^{1}$ one related to voltage-gated membrane channels, mainly the hyperpolarization-activated cationic current $\mathrm{I}_{\mathrm{f}},{ }^{2}$ the other linked to the intracellular calcium handling via the $\mathrm{Na}^{+} / \mathrm{Ca}^{2+}$ exchanger, which, activated by the release of

Correspondence: Francesca Cacciani, Department of Biosciences, University of Parma, Parco Area delle Scienze 11A, 43124 Parma, Italy. Tel. +39.0521.902111 - Fax: +39.0521 .347038 .

E-mail: francesca.cacciani@unipr.it

Key words: sinoatrial node, Ivabradine, Ryanodine, cardiac rhythm, cardiac action potential.

(C) Copyright F. Cacciani and M. Zaniboni, 2014

Licensee PAGEPress, Italy

Journal of Biological Research 2014; 87:2125

doi:10.4081/jbr.2014.2125

This article is distributed under the terms of the Creative Commons Attribution Noncommercial License (by-nc 3.0) which permits any noncommercial use, distribution, and reproduction in any medium, provided the original author(s) and source are credited. calcium by sarcoplasmic reticulum, provides a cyclic source of inward current. ${ }^{3}$ The relative contribution of these two mechanisms to cardiac pacemaking is still debated, and their regulation is of great clinical and pharmacological interest. The aim of our study was to compare the effect of $3 \mu \mathrm{M}$ Ivabradine (IVA) - a specific $\mathrm{I}_{\mathrm{f}}$ blocker $-{ }^{4}$ and of the same concentration of Ryanodine (RYA) - blocker of sarcoplamic calcium release channels $-^{5}$ on action potential (AP) parameters of spontaneously beating single cells isolated from guinea-pig sinoatrial node. Analogous studies had been previously performed on different species. $^{6}$

\section{Materials and Methods}

Sinoatrial pacemaker cells, enzimatically isolated from guineapig hearts (male Dunkin Harley weighing 300-400 gr) ${ }^{2}$ were transferred in the cell chamber of an inverted microscope, and perfused in physiological normal tyrode (NT) solution at $36^{\circ} \mathrm{C}$. Only cells displaying spontaneous and regular contractions were brought in patch-clamp whole cell configuration, and underwent membrane potential recordings.

For each of these cells, a sequence of spontaneous APs was recorded for 2-3 min, until a steady-state AP waveform was reached; perfused solution was then rapidly switched, by means of an electrovalve, to 3 $\mu \mathrm{M}$ IVA solution, and spontaneous APs recorded until a new steadystate was gained (usually 3 to $5 \mathrm{~min}$ ), then again to NT until the recovery of the initial intrinsic configuration was achieved. This protocol was applied to 20 cells; only 7 of them lasted long enough into the whole cell patch clamp configuration to allow testing of $3 \mu \mathrm{M}$ RYA solution as well.

Data analysis was performed by means of a dedicated software (Scaldyn), which we developed in collaboration with the University of Utah. ${ }^{7}$ Scaldyn calculates automatically, for each beat, the cycle length (CL, ms) (the inverse of the pacing frequency) as the distance between two consecutive peaks of first order derivative of membrane potential (dV/dt), and diastolic depolarization rate (DDR, V/s) as the mean value of $\mathrm{dV} / \mathrm{dt}$ calculated in the diastolic depolarization interval. The latter was defined as the time elapsed from the maximum diastolic potential to the peak of the second order derivative of membrane potential.

\section{Results}

Figure 1 shows representative examples of the effect of IVA (top) and RYA (bottom) on APs (Figure 1A) and CL (Figure 1B). The broken arrows indicate the time when the blockers were applied. The increase in CL started just a few seconds after the switch of the solutions, and 
it ended with the reaching of a new steady-state. Though the time taken to reach this new steady state is quite different in the examples shown, no stastical difference was found between IVA and RYA, when this parameter was measured on the total population of 7 cells.

As shown in Figure 2, for $\mathrm{n}=7$ cells, both blockers displayed a comparable prolongation of CL (27 and 30\%, respectively) with respect to NT, which can be ascribed to the decrease of DDR (by 34 and $42 \%$ ).

\section{Discussion}

Cardiac rhythm disturbances are among the most frequent causes of death. To date, therapeutic approaches have mainly been surgical, whereas available antiarrhythimc agents still show important side effects. Thus, a better understanding of the pacemaking mechanisms is crucial to develop new more efficient and safer pharmacological strategies.

\section{Conclusions}

The results of our study, though preliminary, suggest that both the membrane clock ( $\mathrm{I}_{\mathrm{f}}$ ) and the calcium clock (involving sarcoplasmic reticulum calcium release and $\mathrm{Na} / \mathrm{Ca}$ exchanger activation) contribute

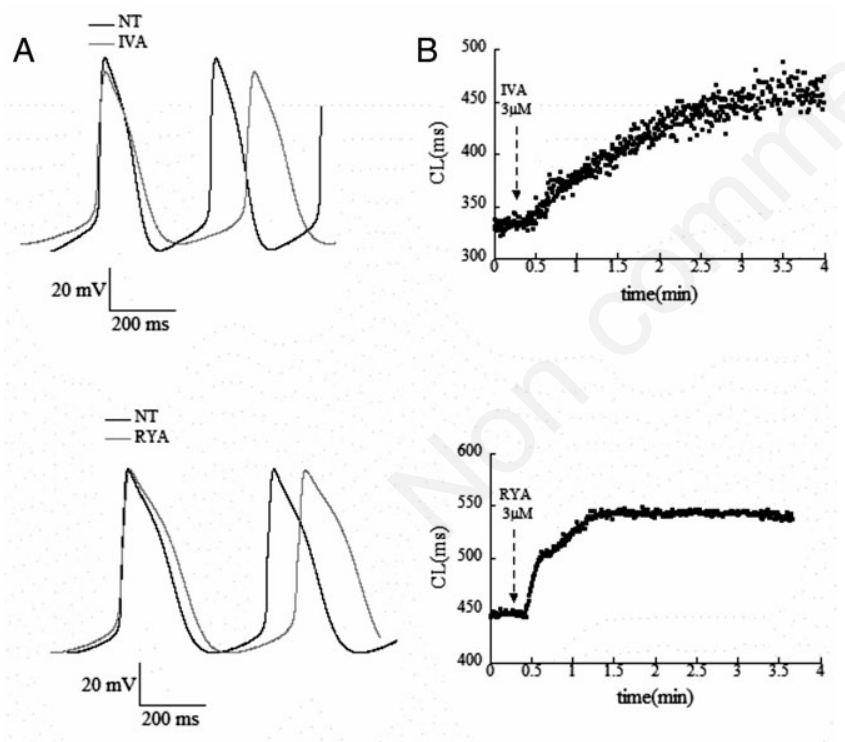

Figure 1. A) Representative examples of the effect of Ivabradine (top) and Ryanodine (bottom) on steady state action potential sequences of guinea-pig sinoatrial cells; controls in black, and blockers in grey. B) Representative examples of time-courses of cycle length following blockers application. Broken arrows indicate the time when the blockers were applied. IVA= Ivabradine; $\mathrm{NT}=$ normal tyrode; $\mathrm{RYA}=\mathrm{Ryanodine}$; $\mathrm{CL}=$ cycle length.

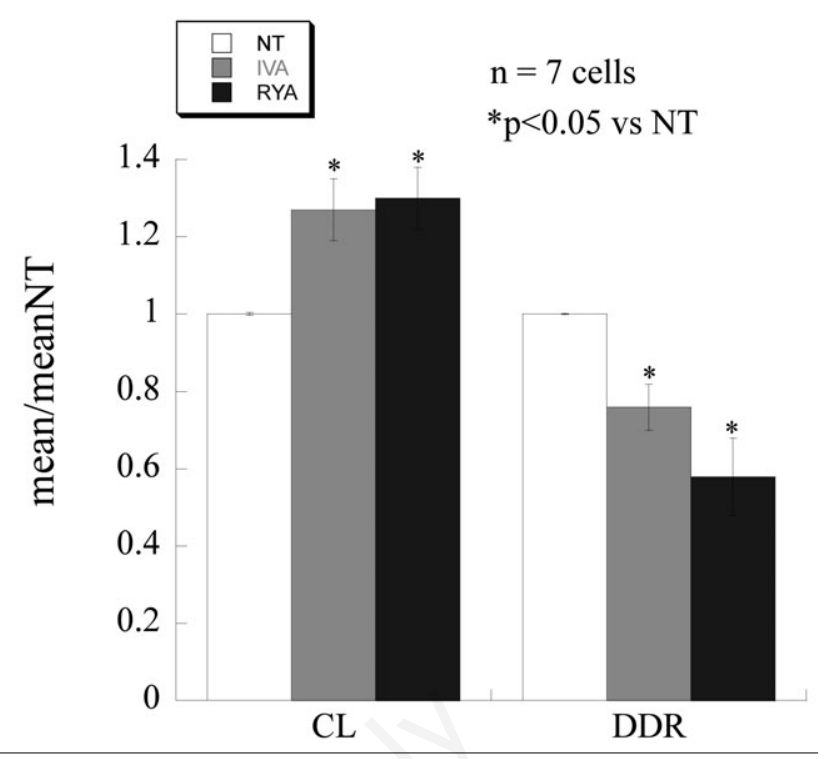

Figure 2. Histogram of the overall effects of blockers on cycle length and diastolic depolarization rate. NT=normal tyrode; IVA= Ivabradine; RYA=Ryanodine.

to cardiac pacemaking to a very similar extent. This might be relevant for developing new pharmacological modulators of cardiac sinus rhythm, to be used in addition, or as substitutes, to the molecules (e.g. Ivabradine, $\beta$-blockers) currently in use.

\section{References}

1. Eisner DA, Cerbai E. Beating to time: calcium clocks, voltage clocks, and cardiac pacemaker activity. Am J Physiol-Heart C 2009;296:H561-2.

2. DiFrancesco D, Ferroni A, Mazzanti M, Tromba C. Properties of the hyperpolarizing-activated current (If) in cells isolated from the rabbit sino-atrial node. J Physiol-London 1986;377:61-88.

3. Bogdanov KY, Vinogradova TM, Lakatta EG. Sinoatrial nodal cell ryanodine receptor and $\mathrm{Na}(+)-\mathrm{Ca}(2+)$ exchanger: molecular partners in pacemaker regulation. Circ Res 2001;88:1254-8.

4. Bucchi A, Baruscotti M, DiFrancesco D. Current-dependent block of rabbit sino-atrial node If channels by Ivabradine. J Gen Physiol 2002;120:1-13.

5. Rousseau E, Smith JS, Meissner G. Ryanodine modifies conductance and gating behavior of single $\mathrm{Ca} 2+$ release channel. Am J Physiol 1987;253:C364-8.

6. Bucchi A, Baruscotti M, Robinson RB, DiFrancesco D. Modulation of rate by autonomic agonists in SAN cells involves changes in diastolic depolarization and the pacemaker current. J Mol Cell Cardiol 2007;43:39-48.

7. Lux RL, Ershler PR. Cycle length sequence dependent repolarization dynamics. J Electrocardiol 2003;36:205-8. 